\title{
AVALIAÇÃO DA CONDIÇÃO GEOMORFOLÓGICA DA BACIA DO RIO MACAÉ - RJ A PARTIR DA METODOLOGIA DE CLASSIFICAÇÃO DOS ESTILOS FLUVIAIS
}

\section{GEOMORPHIC ASSESSMENT OF MACAÉ CATCHMENT - RJ BASED ON RIVER STYLES CLASSIFICATION FRAMEWORK}

\author{
Raphael Nunes de Souza Lima \\ Universidade Federal do Rio de Janeiro, Programa de Pós-Graduação em Geografia - Laboratório de Geomorfologia \\ Ambiental e Degradação de Solos (LAGESOLOS) - Rua Athos da Silveira Ramos, N. 274, Prédio CCMN, Ilha Do \\ Fundão - Rio de Janeiro/RJ - CEP 21941-916 - BRASIL \\ E-mail: raphael.lima@globo.com
}

Mônica dos Santos Marçal

Universidade Federal do Rio de Janeiro, Programa de Pós-Graduação em Geografia - Laboratório de Geomorfologia Ambiental e Degradação de Solos (LAGESOLOS) - Rua Athos da Silveira Ramos, N. 274, Prédio CCMN, Ilha Do Fundão - Rio de Janeiro/RJ - CEP 21941-916 - BRASIL

E-mail:monicamarcal@ufrj.br

\section{Informações sobre o Artigo}

Data de Recebimento:

$05 / 06 / 2012$

Data de Aprovação:

$15 / 08 / 2013$

\section{Palavras-chave:}

Geomorfologia fluvial; estilos fluviais; rio Macaé.

\section{Keywords:}

Fluvial geomorphology; river styles; Macaé river.

\begin{abstract}
Resumo
Diante dos problemas ambientais, que direta ou indiretamente afetam a funcionalidade geomorfológica e ecológica dos rios, a utilização de técnicas para classificação de tipologias fluviais vem se tornando uma metodologia com apelo para a gestão de bacias hidrográficas por permitir compreender as interdependências que ocorrem entre os diferentes trechos do rio desde a nascente até a foz. O presente trabalho foi desenvolvido com o objetivo de analisar tipologias fluviais ao longo de diferentes ambientes na bacia do rio Macaé, contextualizando-os no processo de evolução da paisagem a partir da metodologia de classificação geomorfológica de canais denominada estilos fluviais (river styles). A caracterização de estilos fluviais na bacia do rio Macaé foi realizada a partir de uma rede de avaliação hierarquizada de "parâmetros chave", referente aos principais controles da forma e comportamento do rio, sendo eles: compartimentação geomorfológica; característica do vale; forma em planta do canal; geometria do canal; unidades geomorfológicas; e composição do leito. Com base na metodologia proposta foram identificados sete estilos fluviais cuja diferenciação permitiu compreender, de forma integrada, as formas e processos que caracterizam os diferentes ambientes fluviais, compará-los, assim como identificar sua distribuição espacial na bacia. Neste contexto, o sistema hidrográfico do rio Macaé pôde ser caracterizado como uma grande área de nascentes e canais erosivos que produzem e liberam eficientemente matéria e energia até os compartimentos mais baixos do relevo, que por sua vez o processam com menor velocidade até os trechos retificados, onde há novamente um aumento da capacidade de transporte até a saída do sistema na cidade de Macaé.
\end{abstract}




\begin{abstract}
Given the environmental problems that directly or indirectly affect the rivers' geomorphological and ecological functionality, the use of techniques for classification of river types has become a usefull methodology for watershed management by allowing the understanding of downstram conectivity between different reaches. The present work aimed to analyze river types across different environments in Macaé catchment, contextualizing them in the landscape evolutionary process based on geomorphological classification approach named river styles. The application of the river styles framework in Macaé catchment used a nested hierarchical approach, referring to the main controls of river character and behavior: landscape units; valley setting, channel planform, channel geometry, geomorphic units, and bed material texture. Based on the proposed methodology seven river styles were identified, whose differentiation allowed the characterization of river environments based on its character and behavior, compare them and identify their spatial distribution in the catchment. In this context, the Macaé catchment could be characterized as a large area of springs and erosive channels that produce and release sediments and energy efficiently to the lower compartments of the relief, which in turn process it at a slower speed until rectified reaches where there is again an increase in transport capacity to the system output in the city of Macae.
\end{abstract}

\section{Introdução}

No Brasil, o crescimento urbano acelerado das últimas décadas aliado às dificuldades encontradas pelo poder público em definir regras de uso e ocupação do solo, aumentou a demanda por estratégias de prevenção contra desastres naturais e recuperação de áreas degradadas, sobretudo em função da necessidade de preservar a vida das populações que passaram a viver em áreas de risco e de assegurar os recursos naturais para gerações futuras.

Neste contexto, os rios ganham destaque pelo seu papel de agente esculturador e transformador do relevo e das paisagens, além de disporem de um recurso necessário e indispensável à sustentação da vida: a água.

Diante da gama de problemas ambientais, que direta ou indiretamente afetam a distribuição e a qualidade das águas nos rios, a utilização de técnicas para classificação de tipologias fluviais vem se tornado uma metodologia com apelo para a gestão de bacias hidrográficas por permitir compreender as interdependências que ocorrem entre os diferentes trechos do rio desde a nascente até a foz.

O presente trabalho foi desenvolvido com o objetivo de analisar tipologias fluviais ao longo de diferentes ambientes na bacia do rio Macaé, contextualizando-os no processo de evolução da paisagem a partir da classificação geomorfológica de canais proposta por Brierley \& Fryirs (2005), denominado estilos fluviais (river styles).

Dentre as diferentes abordagens oferecidas pelos esquemas de classificação existentes na literatura científica (Rosgen, 1994; Kondolf, 1995; Kondolf et. al., 2003; Sear, \& Arnell, 2006; dentre outros), o arcabouço conceitual e metodológico dos estilos fluviais oferecem uma proposta estruturada de aquisição, interpretação e de organização de dados voltadas para caracterização de compartimentos que podem ser analisados e comparados para fins de avaliação do estágio de (des)equilíbrio e potencial de preservação/ recuperação dos rios.
Notadamente, diversas aplicações desta metodologia vêm sendo realizadas através de universidades e instituições governamentais em bacias do sudeste da Austrália, Canadá, China, Estados Unidos, Inglaterra e Japão, no âmbito da ecologia de rios, da geomorfologia fluvial e da gestão de bacias (Brierley \& Fryirs 2000).

\section{Caracterização da Área}

A bacia do rio Macaé compreende uma área de aproximadamente $1700 \mathrm{~km}^{2}$, inserida nos grandes lineamentos e fraturamentos do Estado do Rio de Janeiro, com predomínio da direção SW-NE, no qual se encaixa a drenagem principal do rio Macaé. A grande quantidade de fraturas e a resistência das rochas exercem controle estrutural no desenvolvimento da drenagem, principalmente nas áreas centrais da bacia onde são verificados vales em forma de ' $\mathrm{V}$ ', formados pelo entalhamento do rio ao longo de seus planos de falhas. Nas partes baixas da bacia ocorrem ambientes de deposição formados por sedimentos quaternários que recobrem amplas áreas de baixada do rio Macaé, evidenciando um longo período de dissecação e acumulação nos fundos dos vales (Silva \& Cunha, 2001).

A transição do domínio de Escarpas Serranas para Planícies Fluviais gera uma heterogeneidade de ambientes que permite que se estabeleçam ao longo da bacia, diferentes tipos de canais, com padrões de escoamento e descarga de sedimentos diversificados.

Ao longo do processo de uso e ocupação, a área da bacia apresentou diversos impactos diretos, como a retificação de canais aluviais a partir da década de 1960, e indiretos, resultantes do uso e ocupação dos vales, margens e encostas, que impactaram em diferentes níveis na qualidade funcional de seus ambientes (Marçal et al. 2004; FGV Projetos, 2004).

A partir da década de 1980, a chegada da Indústria do Petróleo na bacia de Campos promoveu uma nova dinamização da economia na região Norte do Rio de Janeiro, em 
especial na cidade de Macaé, onde instalaram-se as bases de operações das empresas que exploram na região. Este processo gerou um acelerado crescimento das áreas urbanas, aumentando a demanda por recursos hídricos tanto para abastecimento público como para atividades produtivas (Pessanha \& Neto, 2004).

O ritmo acelerado das transformações sócio-ambientais ocorridas na área de estudo, principalmente a partir de 2001, quando teve início a exploração do petróleo, transformou-a em um cenário dinâmico e campo fértil para o desenvolvimento de estudos que avaliem as variações temporais e espaciais, bem como a multiplicidade de processos gerados a partir das atividades que a sociedade exerce na paisagem.

\section{Classificação geomorfológica de rios e a metodologia dos Estilos Fluviais}

O arcabouço conceitual e metodológico intitulado river styles (estilos fluviais) foi desenvolvido por Brierley \& Fryirs (2005) em parceria com o Conselho Australiano de Conservação da Água (ACWC), sendo os procedimentos específicos da metodologia, uma marca registrada New South Wales Department of Land and Water Conservation e da Macquire University (River Styles ${ }^{\circledR}$ ).

De acordo com os referidos autores, estilos fluviais (river styles) representam uma metodologia de classificação de segmentos do rio que apresentam um conjunto comum de características geomorfológicas e hidrodinâmicas. Esta classificação serve de base para distinguir sistematicamente o caráter (estrutura geomorfológica do rio, incluindo forma em planta e geometria do canal) e comportamento (referente às características hidráulicas do canal, tipo de materiais transportados e depositados, sua relação com a planície e a susceptibilidade a mudanças geomorfológicas) para cada tipo de rio.

Os aspectos geomorfológicos são abordados de maneira hierárquica, onde fenômenos de escala local estão subordinados aos de escala regional. A abordagem dos estilos fluviais orienta a otimização do uso de informações geográficas, ajudando a diferenciar os aspectos que podem ser relevantes dos que representam informações adicionais supérfluas dentro do contexto ambiental sob investigação (Quadro 1).

A utilização deste sistema de classificação permite identificar as relações entre processos e formas ao longo dos rios sob a perspectiva de que estes ocupam um lugar dentro do contexto da paisagem e da bacia, reconhecendo que um rio faz parte de um sistema físico com uma história evolutiva. Dessa forma, um só rio pode apresentar diferentes estilos fluviais; o que implica que cada segmento do seu curso pode interagir de maneira particular com a paisagem em seu entorno.
Quadro 1 - Escalas de análise na metodologia dos estilos fluviais: $O$ arcabouço metodológico dos estilos fluviais é organizado em uma rede hierárquica de escalas que compreende avaliações no âmbito da bacia até as unidades geomorfológicas.

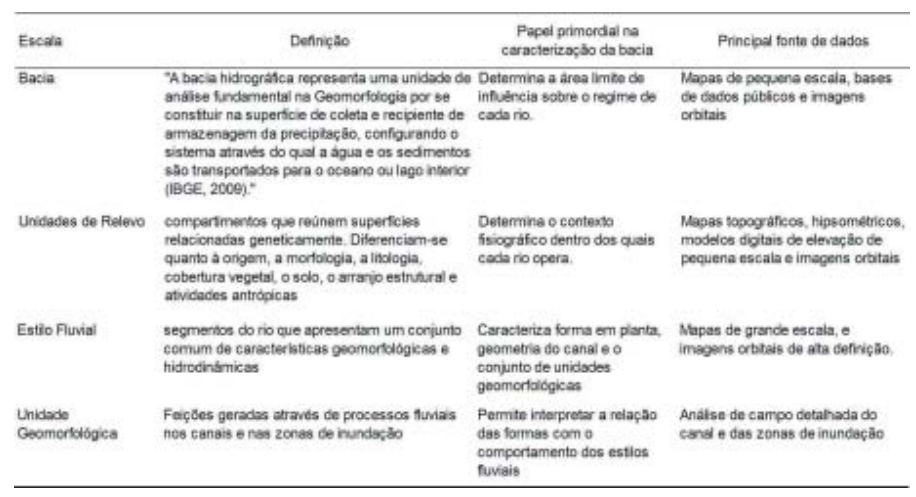

\section{Materiais e Métodos}

A caracterização de estilos fluviais na Bacia do rio Macaé foi realizada a partir de uma rede de avaliação hierarquizada de "parâmetros chave", referente aos principais controles da forma e comportamento do rio, sendo eles: compartimentação geomorfológica; característica do vale; forma em planta do canal; geometria do canal; unidades geomorfológicas; e composição do leito (Figura 1).
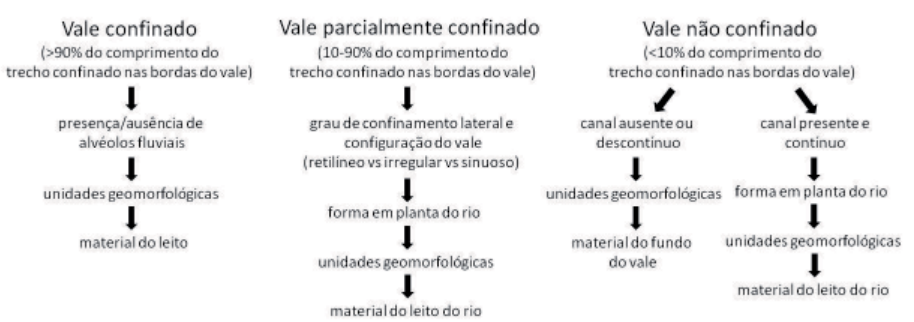

Figura 1 - Arcabouço metodológico e hierarquia dos parâmetros chave para definição de estilos fluviais.

$\mathrm{Na}$ abordagem regional, a Compartimentação Geomorfológica foi realizada por Lima (2010) com base na identificação de diferentes feições morfológicas a partir de índices de amplitude altimétrica, reconhecidos com base na análise de cartas topográficas na escala de 1:50.000 do IBGE, procedimento adaptado por Silva (2002).

Em relação às características dos vales foram definidas em três classes com base na análise do grau de confinamento proposto por Brierley \& Frirys (2005) e adaptado para o contexto de regiões tropicais, onde: Confinado, indica ocorrência de controle litológico de modo que o traçado do rio acompanha o alinhamento do vale. Caracteriza-se por apresentar mais de $90 \%$ do comprimento do canal confinado pelo 
substrato rochoso. Parcialmente Confinado, indica formação de planícies semi-continuas, sinuosas, irregulares e assimétricas. O rio apresenta grande variação na sua morfologia e dinâmica, alternando em áreas de alta e baixa energia como soleiras e depressões. Nesses trechos do rio 10-90\% incidem diretamente sobre rochas ou material coeso. Não Confinado indica maior capacidade de ajuste do canal e instabilidade das margens devido à ausência de controles litológicos. São geradas nesses trechos feições morfológicas como barras e ilhas arenosas, onde menos de $10 \%$ do trecho do rio está apoiado no substrato rochoso ou em terraços, apresentando planícies contínuas e extensas.

$\mathrm{Na}$ abordagem de detalhe, a forma em planta do canal foi analisada e interpretada segundo caracterização proposta por Kellerhals et al. (1976) e Brierley \& Fryirs (2005), considerando o Número de Canais, Sinuosidade (grau de sinuosidade e tipos de sinuosidade), Estabilidade Lateral do Canal (desenvolvimento e crescimento de meandros, grau de entrelaçamento e características do entrelaçamento) e Unidades Geomorfológicas (barras, ilhas, etc.). Nesta etapa foi utilizado um mosaico de imagens orbitais de alta definição obtidas através do programa Google Earth ${ }^{\mathrm{TM}}$, em escala aproximada 1:2.000. As imagens estão disponibilizadas em diferentes datas compreendidas no período de 2003 a 2011, o que possibilitou a análise temporal dos trechos dos rios em até quatro momentos distintos.
Para caracterização do material do leito foram realizadas coletas de sedimentos no talvegue do canal seguidas de análise granulométrica através do método de Wenthworth (1922), que consiste em uma escala logarítmica de classificação granulométrica dos fragmentos de sedimentos clásticos (ou detríticos).

A apresentação dos dados foi realizada através do mapeamento dos limites de cada estilo fluvial, em diferentes simbologias, identificado ao longo do rio Macaé e seus principais tributários e através da elaboração um Quadro de atributos apresentando os parâmetros inventariados para cada Estilo Fluvial identificado.

\section{Resultados e Discussões}

Foram identificados cinco compartimentos geomorfológicos distintos, variando de acordo com o desnivelamento altimétrico: Planícies Fluviais (até 20 metros), Colinas e Morros (20 a 200 metros), Morfologias de Transição e Escarpas Serranas (acima de 200 metros). A Compartimentação Geomorfológica da bacia demonstra três níveis altimétricos condicionados pela própria estruturação geológica da região, sendo eles representados pela Serra do Mar e suas escarpas; a superfície de aplainamento que se desenvolve em direção ao litoral; e as Planícies Fluviais e Flúvio-Marinhas (Figura 2).

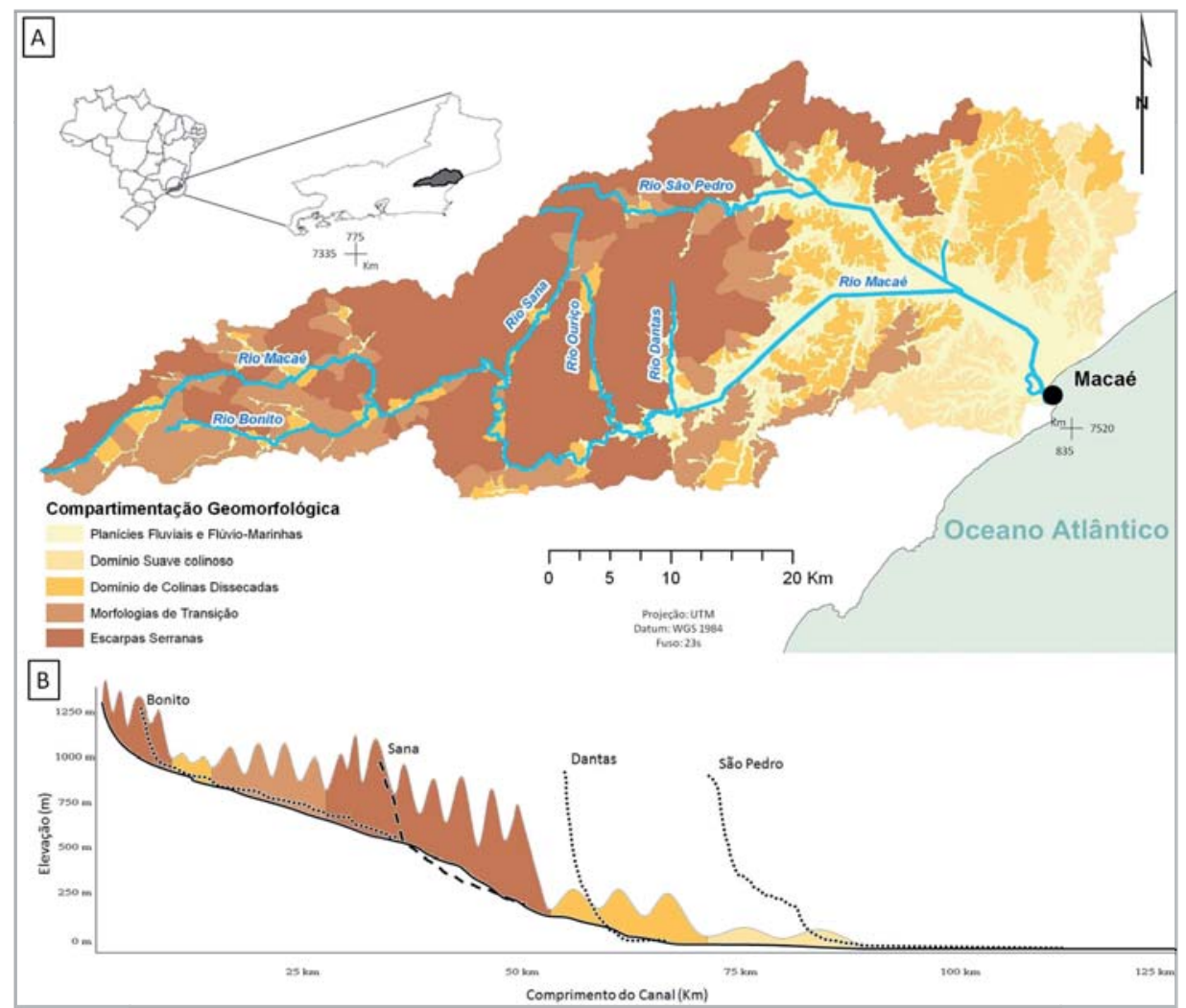

Figura 2 - Mapa de localização e compartimentação geomorfológica da bacia do rio Macaé - RJ. (A) Esta análise regional define o contexto geomorfológico da bacia hidrográfica e agrega informações necessárias para compreender os controles sobre o rio e explicar os padrões de comportamento que se desenvolve para jusante. $61 \%$ da bacia do Macaé representam zonas de produção de sedimentos onde predominam Morfologias de Transição e Escarpas Serranas. O restante da bacia corresponde a uma extensa Planicie Fluvial e Flúvio-Marinha (31\%), onde predominam processos de transferência de materiais. (B) A presença de rupturas de declive e a forma convexa dos perfis longitudinais do rio Macaé e seus principais afluentes, Bonito, Sana e São Pedro reflete o controle do compartimento Escarpas Serranas em que estão inseridos. Já no rio Dantas verificase a forma côncava em seu perfil, notadamente em função da presença do compartimento Planície Fluvial. 
A distribuição espacial destes compartimentos representa o controle primário para o desenvolvimento de diferentes feições e processos fluviais que se somam ao longo do curso do rio, e de maneira contínua, determinam os padrões de comportamento, em cada setor.

\section{Estilos fluviais no rio Macaé}

A nomenclatura escolhida para cada trecho do rio não é pré-estabelecida, mas deve ser dada para que represente o trecho mapeado da forma mais elucidativa possível, buscando resumir as principais características e utilizar, quando possível, nomes ou termos já empregados na literatura. Com base na metodologia proposta foram identificados sete estilos fluviais cuja diferenciação entre as tipologias permitiu compreender, de forma integrada, as formas e processos que caracterizam os diferentes ambientes fluviais, compará-los, assim como identificar sua distribuição espacial na bacia (Figura 3, Quadro 2 e Quadro 3).

A

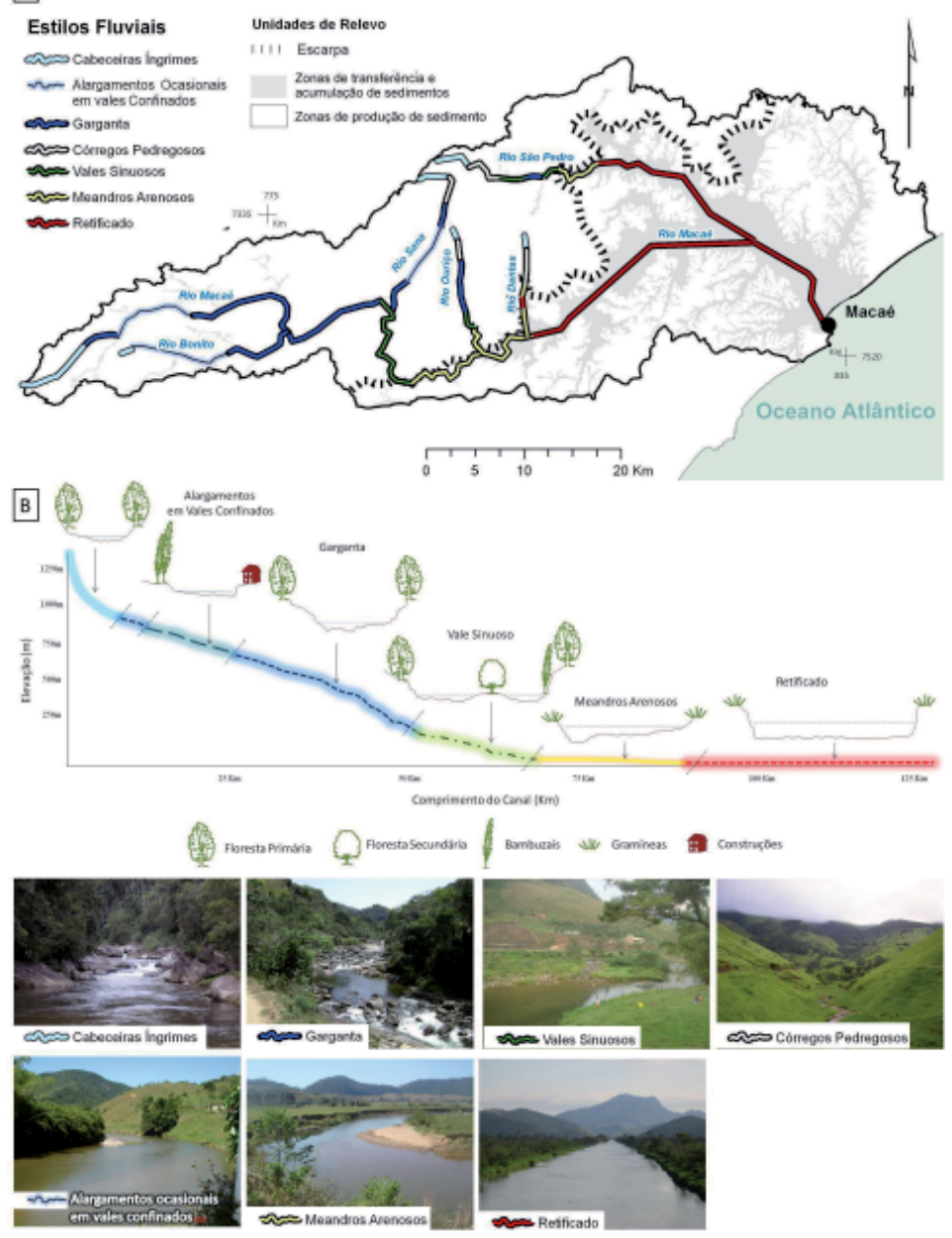

Figura 3 - Distribuição espacial dos estilos fluviais na bacia e ao longo do perfil longitudinal do rio Macaé. (A) Sete estilos fluviais foram classificados na bacia do rio Macaé. Cinco variações ocorrem no dominio Escarpa Serrana, em ambientes confinados ou parcialmente confinados, caracterizados como zonas de produção de sedimentos. Dois estilos fluviais ocorrem no domínio das Planícies, em ambientes não confinados, caracterizando zonas de transferência e acumulação de sedimentos. (B) Dada a complexidade do relevo, controles locais permitem o estabelecimento de diferentes comportamentos para os canais. Mudanças no contexto geomorfológico podem induzir variações no gradiente longitudinal, exercendo controle sobre as formas e o comportamento que se desenvolvem ao longo do rio. Mudanças na geometria e das unidades geomorfológicas que ocorrem no canal acompanham as mudanças do seu gradiente. Fotos: Lagesolos/UFRJ.

Quadro 2 - Atributos distintivos dos estilos fluviais na bacia do rio Macaé.
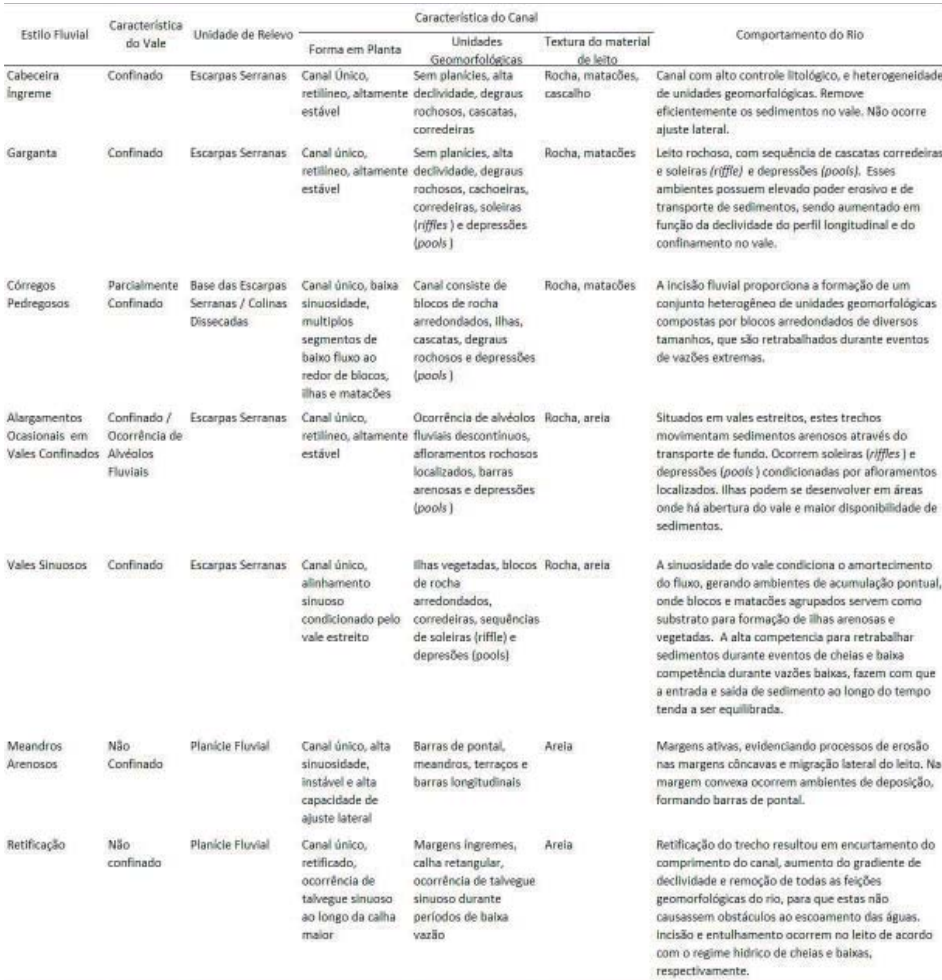

Quadro 3 - Atributos de controle acerca do caráter dos estilos fluviais do rio Macaé

\begin{tabular}{|c|c|c|c|c|c|c|c|c|}
\hline Estilo Fluvial & $\begin{array}{l}\text { Comprimento do } \\
\text { trecho }(\mathrm{km})\end{array}$ & Eleva & ão (m) & Desnivel $(m)$ & $\begin{array}{l}\text { Declividade } \\
\text { Média }\end{array}$ & $\begin{array}{c}\text { Área de } \\
\text { Contribuicão } \\
\left(\mathrm{km}^{2}\right)\end{array}$ & $\begin{array}{l}\text { Largura do } \\
\text { Vale }(\mathrm{m})\end{array}$ & $\begin{array}{l}\text { Largura média } \\
\text { do Canal }(\mathrm{m})\end{array}$ \\
\hline $\begin{array}{l}\text { Cabeceira Íngreme } \\
\text { Alargamentos }\end{array}$ & 10 & 1580 & 970 & 610 & $6,1 \%$ & 51 & 20 & 4 \\
\hline Ocasionais em Vales & & & & & & & & 10 \\
\hline Confinados & 15 & 970 & 813 & 157 & $1,1 \%$ & 40 & $20-200$ & \\
\hline Garganta & 30 & 813 & 236 & 577 & $2,0 \%$ & 266 & $10-40$ & 25 \\
\hline Vales Sinuosos & 15 & 236 & 45 & 191 & $1,2 \%$ & 183 & $10-200$ & 45 \\
\hline Meandros Arenosos & 19 & 45 & 4 & 41 & $0,2 \%$ & 203 & $500-1.000$ & 40 \\
\hline Retificação & 38 & 4 & 0 & 4 & $0,01 \%$ & 1038 & 3.000 & 50 \\
\hline TOTAL & 127 & 1580 & 0 & 1580 & $1,2 \%$ & 1781 & - & - \\
\hline
\end{tabular}

O estilo fluvial Cabeceiras Íngremes (Steep Headwater) ocorre predominantemente no Domínio Montanhoso, com amplitudes altimétricas que variam entre $200 \mathrm{~m}$ e $400 \mathrm{~m}$. Apresentam uma grande variabilidade de unidades geomorfológicas, como leito formado por cascalho, blocos, 
matacões e areia grossa, conferindo caráter de confinamento e estabilidade ao canal. A sinuosidade é baixa e o gradiente longitudinal apresenta média de $6 \%$ de declividade, formando quedas d'água ocasionalmente.

O estilo fluvial Garganta (Gorge) ocorre no Domínio Escarpas Serranas em vales profundos e incisos em forma de 'V' com amplitude topográfica nos vales superior a $400 \mathrm{~m}$. Trata-se de um estilo fluvial cujo leito é rochoso e ocupa todo o fundo do vale não ocorrendo nesses ambientes feições como planícies de inundação ou alvéolos fluviais. Compreende alternância de soleiras e depressões (rifflel pools), além de trechos de corredeiras e ocasionalmente quedas verticais.

A heterogeneidade de ambientes formados no leito e nas margens, das Cabeceiras e Gargantas, somada à condição intacta da vegetação ripária, dá a esses estilos fluviais uma elevada disponibilidade de habitat.

No Domínio Montanhoso ocorrem zonas de formação de alvéolos fluviais decorrente do distanciamento das vertentes do vale. Nestes ambientes ocorre o estilo denominado Alargamentos Ocasionais em Vales Estreitos (Confined Valley With Occasional floodplain Pockets). Situados em vales estreitos, estes trechos movimentam sedimentos arenosos através do transporte de fundo. Ocorrem soleiras (riffles) e depressões (pools) condicionadas por afloramentos localizados. Ilhas podem se desenvolver em áreas onde há abertura do vale e maior disponibilidade de sedimentos.

O estilo fluvial Vale Sinuoso (Troughput), é encontrado em vales estreitos, assimétricos e sinuosos na transição do Domínio Escarpas Serranas para o Domínio Colinoso. A sinuosidade do canal é condicionada pela orientação das vertentes, apresentando meandros estruturais. O canal é estável, constantemente ocupa todo o fundo do vale e atua como um transportador de sedimentos. A taxa de acúmulo ou erosão no leito neste setor da bacia indica o volume de material em movimento pelo sistema e a eficiência do fluxo em retrabalhálos. As curvas fechadas e o aporte de tributários formam zonas propensas à ocorrência de ilhas, frequentemente vegetadas.

Na base das escarpas localizadas nos domínios Montanhosos ocorre o estilo fluvial Córregos Pedregosos (Bedrock Controlled Boulders). Porções de blocos e matacões oriundos das vertentes estreitas encontram-se depositados no fundo do vale. A incisão fluvial induz, por sua vez, a formação de um conjunto heterogêneo de unidades geomorfológicas compostas por estes materiais que são retrabalhados durante eventos de vazões extremas. O gradiente longitudinal deste estilo fluvial é mais baixo que dos descritos anteriormente, apresentando uma média de $0,8 \%$ ao passo que os demais ocorrem acima de 1,2\%. A ocorrência de corredeiras ou quedas são pontuais e localizadas.

A ampla planície aluvial situada no baixo curso do rio Macaé apresenta dois estilos fluviais, atuando sob o regime Não-Confinado. O estilo fluvial Retificado (Streightening) é marcadamente representado pela modificação do leito natu- ral por ação antrópica devido a intervenções em seu traçado original e na geometria de seu canal através de obras de retificação e alargamento. $\mathrm{O}$ canal apresenta leito arenoso, calha retangular relativamente simétrica e com ausência de unidades geomorfológicas. É capaz de suportar as vazões de cheias normais e transferir sedimentos grosseiros até o estuário. O estilo fluvial Meandros Arenosos (Meandering, Sand) apresenta padrão meândrico, com baixo gradiente de declividade $(0,2 \%)$, alta sinuosidade e capacidade de ajuste lateral. São caracterizados por deposição em barras laterais pontuais nas margens convexas das curvas e margens côncavas susceptíveis à ação erosiva.

\section{Capacidade de Ajuste}

De acordo com Brierley \& Fryirs (2005), a diversidade de condições nas quais os processos fluviais atuam permite que, de um trecho para outro, haja considerável variabilidade nos tipos de atributos morfológicos capazes de operar ajustes, bem como na velocidade que tais ajustes podem ocorrer.

Portanto, a capacidade natural de ajuste, definida pelos autores, é aqui compreendida como a adaptação harmônica de morfologias de maneira a reorganizarem-se e disporem-se de modo afim ou equilibrado.

Coletivamente, os ajustes atuantes na morfologia, resultantes de uma série de mecanismos de erosão ou deposição na escala do canal, são definidos como comportamento do rio. $\mathrm{O}$ comportamento pressupõe condições relativamente uniformes e permanentes em longos períodos de tempo.

Esta abordagem conceitual fundamental, que diferencia ajuste, comportamento e mudança, busca identificar se os ajustes em curso fazem parte do regime de comportamento esperado para o tipo de rio, ou se mudanças na relação processo-forma estão provocando transformações para um tipo diferente de rio. Identificar a propensão a ajustes e o modo como estes procedem nos canais compreende, portanto, uma proposta de avaliação da trajetória e evolução de sistemas dinâmicos.

$\mathrm{Na}$ bacia do rio Macaé todos os canais confinados apresentam potencial a ajustes limitado ou inexistente (Quadro 4). Os estilos que se desenvolvem neste ambiente apresentam leitos rochosos ou parcialmente rochosos, que tornam as margens estáveis contra a erosão e não favorecem processos de deposição persistentes. No caso do estilo fluvial Vale Sinuoso, rupturas de declive, associadas à assimetria das vertentes propicia a formação de ilhas, e barras que podem sofrer ajustes, mas dado o caráter de confinamento, não há ajustes laterais. Nos trechos parcialmente confinados ou com aberturas localizadas (alvéolos), podem ocorrer ajustes moderados e localizados. No trecho não confinado ocorre a maior capacidade de ajuste (Quadro 4). O estilo fluvial Meandros Arenosos apresentam remobilização de barras arenosas, erosão nas margens e migração lateral decorrentes das variações 
de vazão. Apesar de não estar confinado, o trecho Retificado não processa ajustes laterais significativos, apenas erosão localizada e de intensidade moderada nas margens, estando o leito mais propenso a ajustes (Quadro 4).

\section{Quadro 4 - Capacidade de ajuste dos Estilos Fluviais na bacia do Rio Macaé}

\begin{tabular}{|l|l|l|l|l|}
\hline \multicolumn{1}{|c|}{ Estilo Fluvial } & Atributos do Canal & $\begin{array}{c}\text { Forma em Planta do } \\
\text { Canal }\end{array}$ & Caráter do leito & $\begin{array}{c}\text { Capacidade natural } \\
\text { de ajuste }\end{array}$ \\
\hline Confinado & & & & Baixa \\
\hline Cabeceras İngremes & & & & Baixa \\
\hline Garganta & & & & Baixa \\
\hline Vale Simuoso & & & & \\
\hline
\end{tabular}

Parcialmente Confinado

\begin{tabular}{|l|l|l|l|l|}
\hline Córregos Pedregosos & & & & Moderada \\
\hline $\begin{array}{l}\text { Alargamentos Ocasionais } \\
\text { em Vales Estreitos }\end{array}$ & & & & Moderada \\
\hline
\end{tabular}

Não Confinado

\begin{tabular}{|l|l|l|l|l|}
\hline Meandros Arenosos & & & Alta \\
\hline Retificado & & & Moderada \\
\hline & $\begin{array}{l}\text { Pontencial de ajuste minimo ou inexistente } \\
\text { Pontencial de ajuste localizado / moderado } \\
\text { Potencial de ajuste alto }\end{array}$ & \\
\hline
\end{tabular}

\section{Evolução e Reversibilidade}

A evolução recente da paisagem da bacia do rio Macaé enfoca os trechos mais suscetíveis a ajustes, que são os estilos fluviais Meandros Arenosos e Retificado.

Estes trechos situam-se no contexto de ambientes não confinados, apresentando uma dinâmica geomorfológica ativa em resposta a chuvas intensas e alterações diretas na calha (Figura 3).

No estilo fluvial Meandros Arenosos, o verão proporciona um comportamento erosivo no leito e margens, ao passo que no inverno predomina uma tendência à deposição (Marçal, 2013). Apesar de ser um comportamento natural deste tipo de canal, a velocidade com que o alargamento e a migração do canal têm operado na última década, pode ser um indicador de ajustes do canal frente à entrada de vazões extremas registradas no período (Quadro 4).

O estilo fluvial Retificado caracteriza-se pelo conjunto de obras de alteração de percurso e de geometria da seção, realizadas pelo extinto DNOS (Departamento Nacional de Obras e Saneamento) com o objetivo de acelerar o escoamento das águas em eventos de cheias e diminuir áreas alagadas. Essa intervenção encurtou o trajeto do canal, aumentou o gradiente de declividade do perfil longitudinal, e removeu todas as feições geomorfológicas do rio, para que estas não causassem obstáculos ao escoamento das águas. Estes procedimentos desencadearam uma série de reajustes na dinâmica de deposição e erosão que ainda não se encontram estabilizados (Quadro 4).

Em ambos os trechos ocorrem atividades de extração de areia, e captação de água, cuja influência para a dinâmica geomorfológica, em especial em períodos de baixa vazão, ainda é objeto de estudo (Assumpção \& Marçal 2012).

Considera-se pelos estilos fluviais identificados, que a bacia do rio Macaé apresenta conectividade entre os subambientes, havendo entrada e a saída dos sedimentos no sistema em função do relevo acidentado em grande parte da bacia, garantindo tanto a produção, como transferência dos materiais oriundos das encostas pelos canais coletores até os trechos baixos, mais suscetíveis a ajustes.

\section{Condição Geomorfológica}

A configuração geomorfológica da bacia apresenta $61 \%$ do sistema hidrográfico compreendido por zonas de produção de sedimentos, drenadas por estilos fluviais com elevada energia e potencial erosivo.

Nestas regiões, ocorrem cinco dos sete estilos fluviais identificados na bacia. Tal diversidade ocorre em função da complexidade do relevo no domínio das Escarpas Serranas, onde são observados controles locais como variações no declive do perfil longitudinal; sinuosidade e grau de confinamento dos vales produzindo diferentes comportamentos e feições nos rios (Figura 3 e Quadro 2).

Apesar das áreas florestadas, em regiões elevadas da bacia, apresentarem bom estado de conservação, a ausência de práticas de manejo conservacionistas e ocorrências de desmatamento têm contribuído para o aumento da erosão em lençol e da probabilidade ocorrência de processos de movimentos de massa, dada à erodibilidade intrínseca dos solos dessa região.

Os estilos fluviais que desenvolvem-se em ambientes confinados são resilientes a eventos de aporte sedimentar de maior magnitude, uma vez que não operam ajustes laterais significantes e apresentam elevada capacidade de transferir sedimentos.

Já nas zonas de transferência, que correspondem à cerca de $525 \mathrm{~km}^{2}$ (29\% da área da bacia), predominam processos de transporte gradual de sedimentos em detrimento da produção (Figura 3 e Quadro 2).

Esta região mais baixa é caracterizada por morros, colinas e planícies fluviais, na qual grande parte da cobertura vegetal original foi suprimida para dar lugar a pastagens e práticas agrícolas (Figura 4). Tais alterações na cobertura vegetal não tiveram impacto significativo para a produção de sedimentos, uma vez que estas áreas possuem suscetibilidade à erosão média e baixa (Brasil, 1983; Carvalho Filho et.al., 
2000), somando-se ao fato de que o sistema encosta-calha é desconectado pela planície fluvial. O rio Macaé e demais canais coletores que drenam as planícies são meandrantes, com energia e capacidade de transporte de sedimentos menor do que os trechos das áreas serranas (Quadro 2). Esta característica os torna mais susceptíveis a ajustes morfológicos caso ocorram mudanças de regime à montante, seja por variações na vazão ou no aporte sedimentar (Quadro 4).

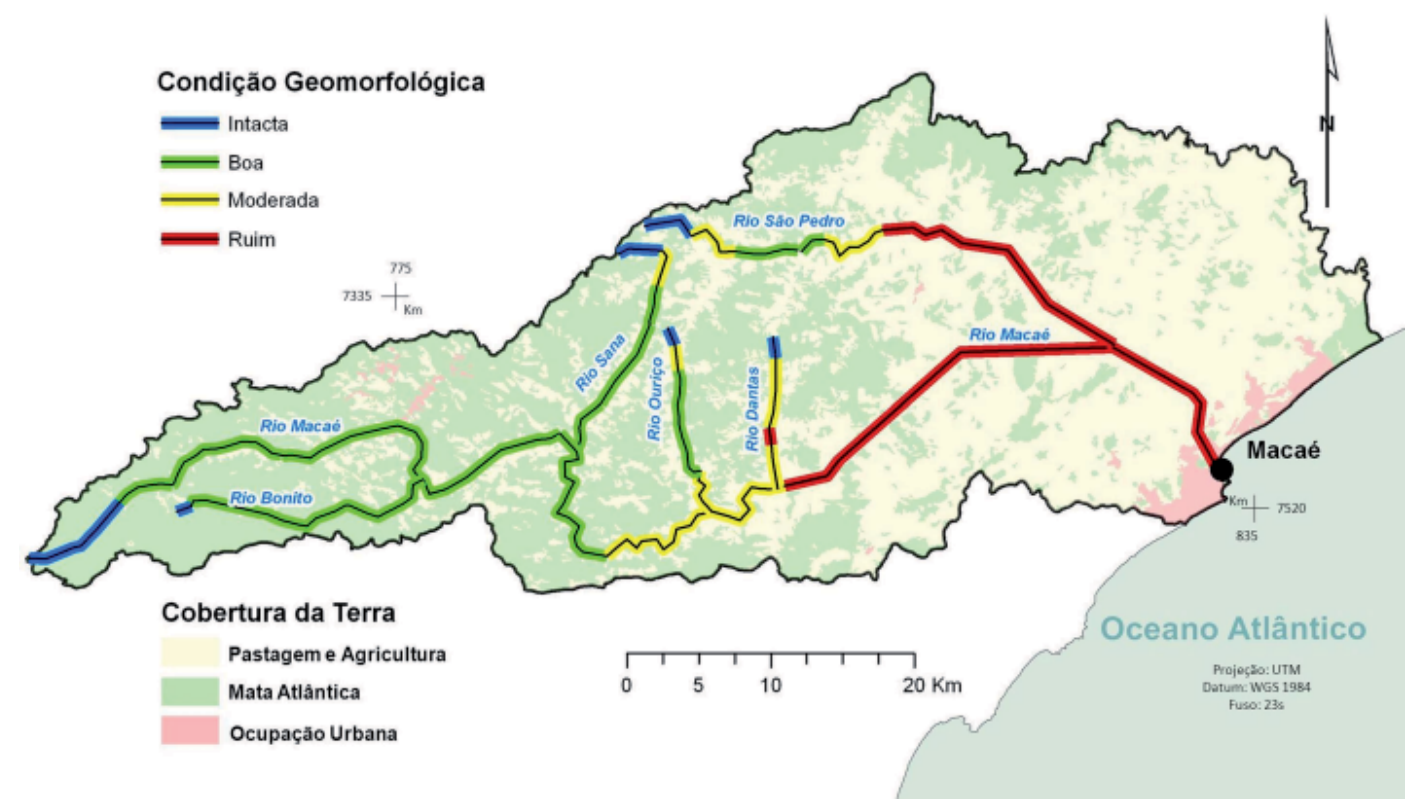

Figura 4 - Condição Geomorfológica: Variabilidade da condição geomorfológica dos rios na bacia do Macaé. Condição intacta e boa restringem-se ao alto curso em trechos confinados. Condições moderadas ocorrem em ambientes parcialmente confinados e não confinados, influenciados principalmente pela ausência de cobertura ciliar e atividades de extração de areia. Condição ruim corresponde ao trecho retificado em que ajustes de incisão não se estabilizaram.

No período de vazão baixa, é possível perceber na calha maior, uma sinuosidade do talvegue através da formação de barras laterais submersas. Durante as cheias, a estrutura do canal permite o escoamento da vazão, elevando a energia e permitindo o transporte de sedimentos grosseiros. As margens desprovidas de mata ciliar apresentam ainda processos erosivos ocasionados durante os regimes de alta energia do rio.

Do ponto de vista geomorfológico os estilos fluviais localizados em ambientes confinados encontram-se em estado de conservação intacto, quando não há alcance de atividades antrópicas capazes de interferências, ou boa quando as feições e comportamentos condizem com os padrões esperados dentro do contexto de seus compartimentos: tamanho, forma do canal e morfologia das margens controladas por estruturas geológicas e materiais antigos (Figura 4). A erosão das margens é insignificante e declives locais induzem o padrão das unidades geomorfológicas, como as sequências de soleiras (riffle) e depressões $(p o o l)$. As transformações no leito ocorrem de forma lenta e gradual, a partir da sequência histórica de transporte sedimentar (variações climáticas) (Quadro 2).

Já os canais inseridos em ambientes não confinados, apresentam condição geomorfológica mais sensível devido a sua capacidade de ajuste lateral e vertical, através do elevado potencial erosivo do leito e de retrabalhamento de feições arenosas (Figura 4).

\section{Conclusões}

A identificação e caracterização dos estilos fluviais no sistema hidrográfico da bacia do rio Macaé permitiu conhecer as características e interações entre sub-ambientes distintos nos canais fluviais e avaliar, juntamente com a compartimentação do relevo, seu comportamento e trajetória de evolução a partir da década de 1960 quando iniciaram as obras de retificação dos canais nas planícies fluviais.

A área de drenagem apresenta grande parte da configuração geomorfológica, $61 \%$ da área total, com o predomínio de vales incisos e confinados. Estes apresentam pouca capacidade de ajustes laterais, com modificações nas margens somente em áreas onde o vale apresenta aberturas em forma de alvéolos de deposição.

Nestas áreas, o elevado número de nascentes e canais erosivos produz e libera eficientemente matéria e energia para os compartimentos mais baixos do relevo, e conferem boa condição geomorfológica aos canais, que são aproveitadas por atividades turísticas, recreativas e esportivas (por exemplo, rafting e canogem).

Já as demais áreas de drenagem, 39\% do total, são definidas como zonas de transição com ocorrência de 
colinas e áreas de planícies, vales semi-confinados e não confinados, onde predominam atividades agropastoris. Nestes ambientes verificam-se as tipologias fluviais com maior potencial a ajustes e mudanças no padrão do canal. A ausência de mata ciliar no trecho Meandros Arenosos e Córregos Pedregosos potencializa a erosão das margens, conferindo uma condição geomorfológica moderada.

No trecho Retificado percebe-se o aprofundamento do leito através de um processo de incisão fluvial resultante do aumento da velocidade de escoamento. A alteração do traçado através da retificação impôs modificações tanto na forma em planta dos canais fluviais, como, também, na dinâmica hidrossedimentológicas que repercutem no sistema hidrográfico da bacia de forma diferenciada, causando instabilidade aos processos erosivos e deposicionais atuais. A mineração de areia no leito também corrobora para uma condição geomorfológica ruim, considerandose que não há registros de volume dragado ou de controle sobre a atividade.

Apesar da condição geomorfológica ser heterogênea ao longo da bacia, as características dos estilos fluviais apresentadas nesta pesquisa apontam para um elevado potencial de reabilitação dos trechos em condição moderada ou ruim, tendo em vista a disponibilidade de sedimentos e energia liberados pelo sistema e conectados através da transferência entre sub-ambientes.

\section{Agradecimentos}

À FAPERJ (Fundação Carlos Chagas Filho de Amparo à Pesquisa do Estado do Rio de Janeiro) e ao CNPq (Conselho Nacional de Desenvolvimento Científico e Tecnológico) pelos auxílios concedidos.

\section{Referências bibliográficas}

ASSUMPÇÃO, A.P.; MARÇAL, M.S. Retificação dos canais fluviais e mudanças geomorfológicas na planície do rio Macaé (RJ). Revista de Geografia (UFPE), v. 29, n. 3, p. 19-36, 2012.

BRASIL. Levantamento Exploratório dos Solos Ministério das Minas e Energia. Projeto RADAMBRASIL, v. 32, Rio de Janeiro - Vitória, Série Levantamento de Recursos Natrurais. 1983. BRIERLEY, G.J.; FRYIRS, K.A. River Styles, a geomorphic approach to catchment characterization: Implications for river rehabilitation in Bega Catchment, NSW, Australia. Environmental Management. New York, US: v. 25, n. 6, p. 661-679. 2000.

BRIERLEY, G.J.; FRYIRS, K.A. Geomorphology and River Management: Applications of the River Styles Framework. Blackwell Publishing, 2005. 398 p.

CARVALHO FILHO, A.; LUMBERAS, J.F.; SANTOS, R.D. LEMOS, A.L.; SANTOS, R.D.; FILHO, B.C.; WITTERN, K.P.;
SOUZA, F.S. Os solos do Estado do Rio de Janeiro. CPRM, Brasília. 2000. 1CD.

FUNDAÇÃO GETÚlIO VARGAS. Projeto de Pesquisa de Estudo de Cheias no Baixo Curso do Rio Macaé, em Especial sobre o Núcleo Urbano, $2^{\circ}$ relatório: Diagnóstico da Situação Atual dos Recursos Hídricos da Bacia do Rio Macaé. p.251. 2004.

FRYIRS, K.A., SPINK, A. BRIERLEY, G.J. Post-European settlement response gradients of of river sensitivity and recovery across the upper Hunter catchment, Australia. Earth Surface Processes and Landforms, UK: v. 34, n.7, p. 897-918. 2009. INSTITUTO BRASILEIRO DE GEOGRAFIA E ESTATÍSTICA. Manual técnico de Geomorfologia. Rio de Janeiro, 2009. 182 p. KELLERHALS, R., CHURCH, M., BRAY, D.I.. Classification and Analysis of river processes. Journal of Hidraulics Division, American Society of Civil Engeneers, v.102, p. 813-829. 1976.

KONDOLF, G.M. Geomorphologycal Stream channel Classification I aquatic habitat restoration: uses and limitations. Aquatic Conservation, v. 5, p. 109-126. 1995.

KONDOLF, G.M.; MONTGOMERY, D.R.; PIEGÁY, H.; SCHMITT, L. Geomorphic Classification of Rivers and Streams. In: KONDOLF, G.M.; PIEGÁY, H. (Orgs.) Tools in Fluvial Geomorphology. John Wiley \& Sons, Ltd. PP.171-204. p 696. 2003.

LIMA, R.N.S.L. Conectividade dos Ambientes Fluviais: Implicações para Avaliação da Sensibilidade do Sistema de Drenagem da Bacia do Rio Macaé (RJ). Dissertação (Mestrado em Geografia) - Instituto de Geociências, Departamento de Geografia, Universidade Federal do Rio de Janeiro, Rio de Janeiro, p.127. 2010.

MARÇAL, S.M. Análise das mudanças morfológicas em seções transversais ao rio Macaé - RJ. Revista Brasileira de Geomorfologia. v.14, n.1, p.59-68, 2013

MARÇAL, M. S. ; LUZ, L. M. ; MARASCHIN, T. Geomorfologia no Planejamento e Gestão da Bacia do Rio Macaé (RJ). In: Simpósio Nacional de Geomorfologia, 5, Santa Maria (RS). Anais... 2004, 1CD.

PESSANHA, R. M.; NETO, R. S. (Org.) Economia e desenvolvimento no norte fluminense: da cana de açúcar aos royalties do petróleo. Campos dos Goytacases, RJ. Editora WTC. p.364. 2004.

ROSGEN, D.L. A classification of natural rivers. Catena, Elsevier Science, .B.V. Amsterdam, v. 22. p. 169-199. 1994.

SEAR, D.A.; ARNELL, N.W. The application of palaeohydrology in river management. Catena, Elsevier Science, .B.V. Amsterdam, v.66, p.169-183. 2006.

SILVA, L.C.; CUNHA, H.C.S. Geologia do Estado do Rio de Janeiro. CPRM, Brasília. 2001. 1CD.

SILVA,T.M.. A Estruturação Geomorfológica do Planalto Atlântico no Estado do Rio de Janeiro. 2002. Tese (Doutorado em Geografia) - Instituto de Geociências, Universidade Federal do Rio de Janeiro, Rio de Janeiro, 265 p.

WENTHWORTH, C.K. A scale of grade and class terms for clastic sediments. Journal of Geology, v. 30. p. 377-392. 1922. 